\title{
Variability of the annual amounts of station precipitation revealed by autocorrelation functions and power spectra
}

\author{
Gyu-Ho Lim(1), Ae-Sook Suh ${ }^{(2)}$, and Yong-Cheol Suh ${ }^{(3)}$ \\ (1) Seoul National University, Seoul 151-747, Republic of Korea \\ gyuholim@snu.ac.kr \\ (2) Hydrometeorological Cooperation Center, Gwacheon-si 11, Gyeonggi-do 427-100, Republic of Korea \\ assuh@partner.kwater.or.kr \\ (3) PuKyong National University, Busan 608-737, Republic of Korea \\ suh@pknu.ac.kr
}

\begin{abstract}
The rainfall in Seoul, comprising "Chugugi" and modern rain-gauge measurements, shows a resilient autocorrelation peak at a time lag of 11 years and a statistically reliable suppression of the 11-year frequency in the associated spectrum function. We confirmed a similar signature in the averages of the autocorrelations and spectra of the Global Historical Climatology Network precipitations. Approximately half of the selected 3,065 stations showed the autocorrelation peak, and the associated power suppression of the 11-year period or frequency. For the global average, the spectrum suppression was pronounced, and the associated correlation peak was less notable. We were able to simulate the suppression of power by modulating white noise time series representing precipitation with a sinusoidal time series of a given frequency. For modulation, we used multiplication instead of addition. The nonlinear process seems to be the principal mechanism in the influence of the 11-year solar cycle on precipitation.
\end{abstract}

Key words: autocorrelation, nonlinear process, precipitation, rainfall, spectrum, suppression.

\section{Variabilidad en la precipitación anual a partir de las funciones de autocorrelación y los espectros de potencia}

\begin{abstract}
RESUMEN
La lluvia en Seúl, comprendiendo tanto "Chugugi" como medidas en pluviómetros modernos, muestra un fuerte pico en la autocorrelación para un paso temporal de 11 años, así como una supresión estadísticamente significativa de la frecuencia correspondiente a 11 años en la función espectral asociada. Se ha confirmado una impronta similar en las medias de las autocorrelaciones y espectros de la precipitación en la Global Historical Climatology Network. Aproximadamente la mitad de las 3065 estaciones seleccionadas mostraron el pico en la autocorrelación, y la supresión del período de 11 años. Para la media global, la supresión en el espectro es pronunciada, y el pico de correlación asociado es menos relevante. Se ha podido simular la supresión de la potencia mediante la modulación de series temporales de ruido blanco que representan precipitación con una serie temporal sinusoidal de una frecuencia dada. Para la modulación se utilizó la multiplicación en lugar de la adición. Un proceso de tipo no lineal parece ser el principal mecanismo en la influencia del ciclo solar de los 11 años en la precipitación.
\end{abstract}

Palabras clave: autocorrelación, Iluvia, espectro, precipitación, proceso no lineal, supresión.

\section{Introduction}

Historical recordings of rainfall are common. People have documented rainfall for a long time compared with other meteorological parameters. The long-term documentation may reflect the importance of rainfall to people in agriculture and food production. Many nations are proud of their long records of rainfall 
amounts, which have varying degrees of accuracy (Kim, 1988). India's rainfall records date back to 1871 (Parthasarathy et al., 1991). Some authors claim 5.1years, 10.4-years, and 18.4-years frequency peaks, as well as other longer term periodicities based on rainfall-related records in the historical documents of Korea and China (Kim, 1976; Zhang, 1999).

Many people have considered the potential effects of sunspot cycles on the weather conditions of the earth. However, we have no clear evidence of linking the surface conditions of mid-latitude Earth to sunspot cycles. As far as the tropical troposphere is concerned, limited studies have been done (Lim et al., 2006; Kossin et al., 2010). We have convincing evidence of solar effects on the stratosphere as revealed in these studies (Labitzke and van Loon, 1993; van Loon and Labitzke, 1998). Many impute the difficulty of determining solar cycle effects on weather formation to the sun's small variability of luminosity resulting from the small variation of sunspot numbers over time (Hartmann, 1994). We will show that this is not the case and that the fundamental problem lies in the conventional interpretation of the results of frequency analysis. We have a clear 11 -year suppression in the spectrum analysis of the Global Historical Climatology Network (GHCN) stations at a global level, not just for Seoul. We have confirmed the possibility of suppression by the 11-year signal instead of a traditional peak in the frequency domain.

As a preliminary analysis of station precipitations, we checked that the time series of annual amounts of precipitation had a small lag 1 autocorrelation value of about 0.0818 and the statistical characteristics of white noise-like processes in its spectra. Accordingly, the power spectrum of the annual amount of precipitation does not show any notable visual peak in general. Consequently, it is difficult to point out any apparent cyclic component in the temporal variation of annual amounts of precipitation. The weak and noisy inter-annual variation of precipitation vividly contrasts with diurnal, semidiurnal, and seasonal variation of precipitation (Lim and Suh, 2000).

There are few opinions about the solar variation's possible effects on the climate of the earth, especially in relation with rainfall amounts. The conclusion is still not definitive because of extremely weak solar variation or due to the strong randomness of the rainfall time series. Previous studies were mostly concerned with the precipitations over a limited area with a limited number of stations. The results are naturally dependent on the characteristic of the local precipitation regimes. At the same time, we have to consider the weakness of the responses of precipitation to the intrinsically weak solar variation. The weakness is the main argument of neglecting any relationship between the sun and the precipitation regime. The argument is quite reasonable if we could rule out nonlinear processes and feedback mechanisms working in the atmospheric motions.

In order to confirm the observed features in the time series of precipitation in the local and global bases, we carried out diverse numerical calculations by assuming simplified conditions. We will explain the observed aspects by examining the autocorrelation and spectrum functions of the assumed time series. The time series are the white noise time series multiplied with a sinusoidal time series in the time domain. The global precipitation seems to respond to the change in the static stability of the atmosphere resulting from the volcanic eruptions ( $\mathrm{Gu}$ and Adler, 2011). The previous anticipation may hold for much weaker signals such as the 11-year solar cycle. We propose that regularity might be more effective in controlling an atmosphere regime than a shock type impact.

This paper contains data sources and processes in subsequent sections. Next section includes descriptions of the rainfall in Seoul and global observation stations. Another section provides numerical experiments with simple and more realistic conditions. The conclusions are in the last section.

\section{Data sets}

In Korea, we have a long rainfall record for Seoul that extends 243 years from 1770 to 2012. Measurements made by the Korean rain gauges were nearly the same as modern rainfall observations except for the coarse resolution of the measuring units and the observation time interval(van Loon and Labitzke, 1993; Chun et al., 2005). The minimum unit of the Korean rain gauge is the "pun", which corresponds to about $2 \mathrm{~mm}$ in modern observations. The observation time interval is about two hours with the modern rain gauge. The start and end times of the rainfall, as well as the total amount were recorded. The maximum period for rainfall accumulation was not allowed to exceed eight hours, which means that at least three observation times were required to document a day of continuous rainfall. The rainfall data from the same source was also used to investigate drought and rainfall variation in Seoul (Wang et al., 2007; Wang et al., 2006).

We retrieved semi-hourly rainfall amounts from the "Seungjeongwon" diary, but only used the annual rainfall. This is suitable for the purposes of this study because our interests are on the sunspot cycle, 
which has a period of approximately 11 years. When documenting Seoul rainfall, many authors have combined the "Chugugi" rainfall records for the years 1770-2006 and the modern rain gauge measurements from 2007 to the present by counting only the different units of measurement in the ancient and present times (Jung et al., 2000; Jung et al., 2001). The practice does not cause any problems, as has been confirmed by many authors. The longest data void is a period of two years and seven months that occurred during the Korean War from 1950-1953. For the Seoul station, we prefer the term "rainfall" instead of "precipitation" because there are no snow measurements in the "Chugugi" data. In Seoul, solid precipitation occupies less than $10 \%$ of the total annual amounts of precipitation as determined by (Jung et al., 2000).

To check and complement any deficiencies in Seoul rainfall records, we downloaded the GHCN precipitation data from the website ftp.ncdc.noaa.gov/ pub/data/ghon, which is managed by the National Center for Environmental Prediction of America. We retained stations with longer than 100 years' data records and which were missing fewer than $10 \%$ of values in the annual precipitation amounts. The distribution of the selected stations is given in Figure 1. Most of the stations are located in North America, Australia, India, and Europe. The effects of such a distribution are not addressed in our analysis. We assumed that the individual time series are nearly independent from each other, without any spatial

\section{Distribution of the stations}

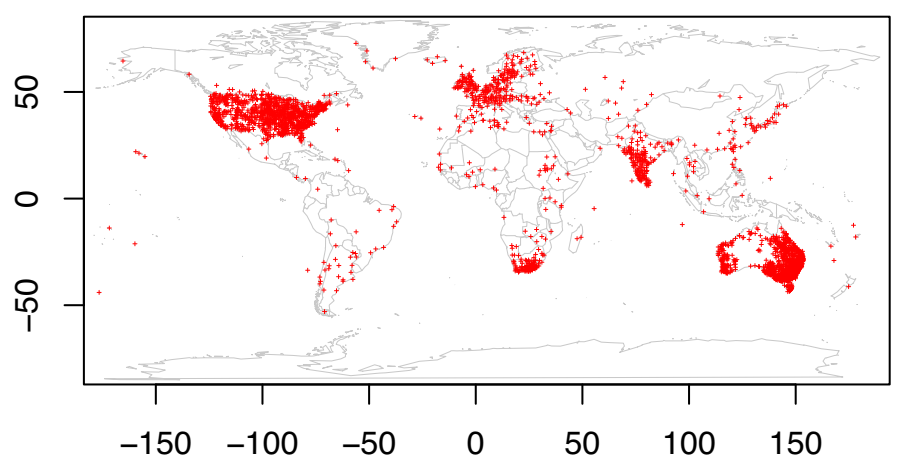

Figure 1. Distribution of the selected GHCN stations whose data period is longer than 100 years. The number of missing records is less than 10 years in total irrespective of their continuance or intermittence. The above criteria retain 3065 stations from the total of 20,590 stations.

Figura 1. Distribución de las estaciones GHCN cuya longitud de datos es mayor a 100 años. El número de registros perdidos es menor a 10 años en total, independientemente de su continuidad o intermitencia. Los criterios anteriores seleccionan 3065 de un total de 20590 estaciones. relationship depending on their separation in distance. The assumption might not be realistic but is acceptable when considering the white noise-like composition of the annual amounts of precipitation. We will examine the locality and spatial relationship of these time series in another study.

There is a minor difference in the total amount of Seoul rainfall amounts based on our retrieval and those from the GHCN. However, most of the statistics of both time series are virtually the same. So we will not differentiate these in this study and will assume that they are the same for the purpose of analysis.

\section{Observed features}

\section{Seoul rainfall}

We can confirm the robustness of the 11-year autocorrelation function (ACF) peak in Figure 2, in which the peak appears even in the time series of the residuals from the three-year moving averages. The moving average may filter out the 5-6 year peak, but strangely it does not eliminate the 11-year correlation peak. The 11-year ACF peak is also insensitive to the magnitude of extreme rainfall values. In order to examine any dependency of the autocorrelation functions on the magnitudes of rainfall amounts, we compared ACFs for different categories of rainfall amounts. The differences are too small to warrant displaying the results.

In our analysis, the 11-year ACF peak was remarkably stable and robust. The ACF showed the tendency of a stochastic process. A stochastic process is hard to resolve with the adoption of sinusoidal functions. The observed ACF peaks were nearly independent of the wax and wane of sunspot numbers and the corresponding up and down of rainfall amounts in general. Consequently, conventional frequency analysis could not capture a spectrum peak to be anticipated, and is even less effective for a delta function like the 11-year ACF peak.

In Figure 3, the disappearance or suppression of an 11-year periodicity is evident in a wavelet analysis of the same time series. The frequency-dependent power distribution as a function of time clearly shows a void of an 11-year period irrespective of time (Fig. 3b). In Figure 3c, the global wavelet power spectra show a similar suppression but it is less remarkable. For analysis, we used the morlet wavelet using a mother wavelet with wave number 6 (Torrence and Compo, 1998). The data set comprises 243 annual amounts of precipitation. It produces the smallest scale at 2 years and the maximum scale at 27 years. 

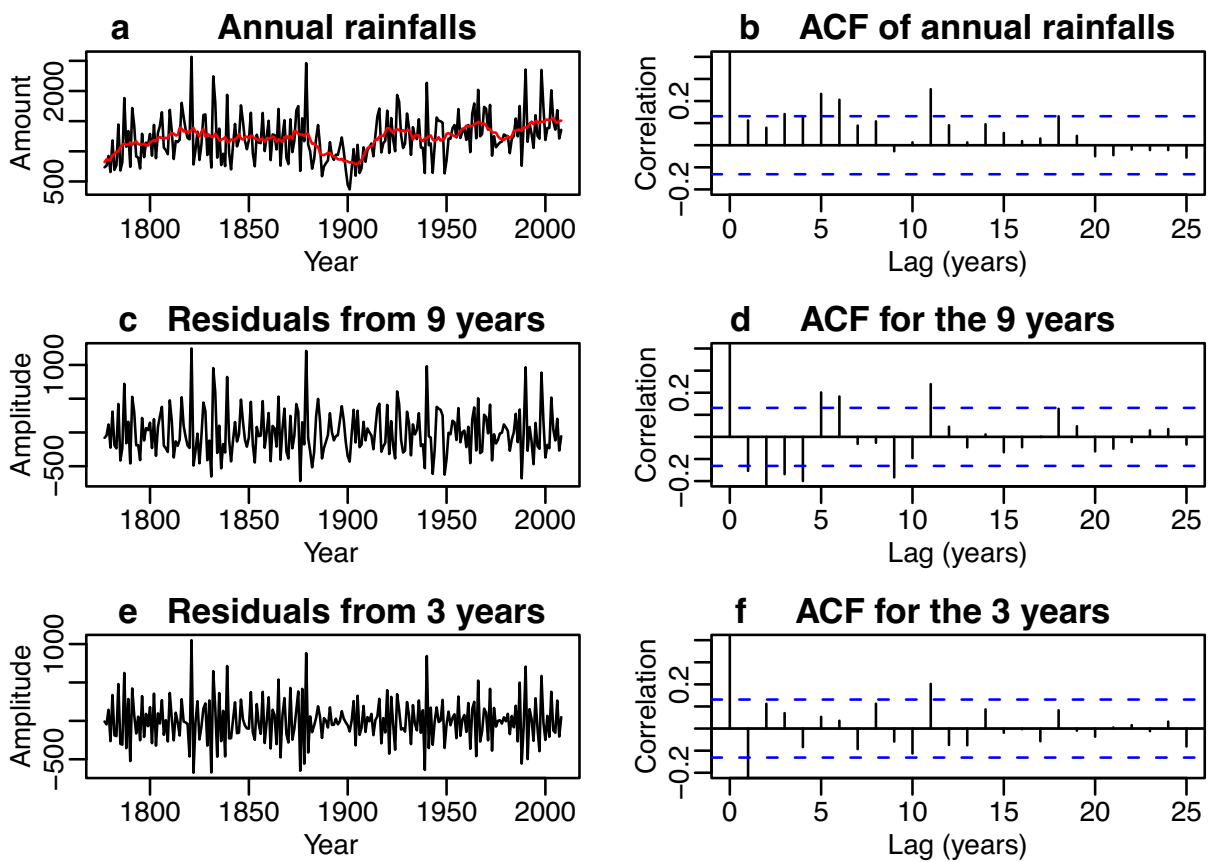

Figure 2. Seoul rainfall time series and their ACFs: (a) and (b) are the annual rainfalls with their 9-year moving averages in red and the ACF of the rainfalls. (c) and (d) are for the time series of the residuals from the 9-year moving averages and its ACF, respectively. (e) and (f) are the same as for (c) and (d) but for the series of residuals from 3-year moving averages. The dashed lines in the right-hand side figures denote $5 \%$ significance level of the random series. The value is $\pm 2 / 243$, where 243 is the total data length.

Figura 2. Series temporales de precipitación en Seúl y sus funciones de autocorrelación: (a) y (b) son las lluvias anuales con su media móvil de 9 años en rojo y la función de autocorrelación de las lluvias. (c) y (d) son las series temporales de los residuos de sustraer de la serie original las medias móviles de 9 años y su función de autocorrelación. (e) y (f) son lo mismo que (c) y (d) pero para las series de residuos utilizando medias móviles de 3 años. Las líneas azules discontinuas en las figuras de la derecha son el nivel de significación del $5 \%$ para series aleatorias. Este valor es $\pm 2 / 243$, donde 243 es el número total de datos.

Each major scale has 4 subscales. The analysis periods cover 2 years to 215 years.

\section{Precipitation of the GHCN stations}

If we accept the intrinsic white noise-like behavior of annual precipitation, it is reasonable to interpret the suppression as being caused by a regular periodic variation such as the solar signal. The precipitation regime of each station seems to be widely variable, as revealed by analysis of the GHCN station precipitations. For example, Seoul (1770-2012) and Incheon (1902-2012) clearly show a peak in the ACF and suppression in the associated spectra. In contrast, it is not feasible to designate a notable autocorrelation value or frequency component for Kew Gardens in England, whose data records are the longest covering 303 years from 1697 to 1999. In our estimation, the notable autocorrelation peak and weak suppression are observed for about half of the selected stations, but some stations showed a clear signature in both.
From all the 3,065 stations, on average, we had more convincing suppression rather than the correlation peak (Fig. 4a).

A minor shift toward a higher frequency of the strongest suppression might come from the intermittence of the precipitation time series. In general, intermittence of a quantity causes a reddening of its time series that is originally white or even blue. Another possible cause of the shift may be associated with the irregular period of solar cycle around 10.5 years and/or not enough number of spectrum lines due to the limited sample number. The sample number used for calculation is close to the average value (120) of the samples for all the selected GHCN stations.

By applying intermittency to a simple but nonlinear model for describing population change in time, they clearly showed the reddening of the time series that was originally white (Balmforth et al., 1999). If we accept the result, we can safely assume the whiteness of the precipitation time series. The observed precipitation may shift its suppression to the higher frequency by various processes in the real world. The 

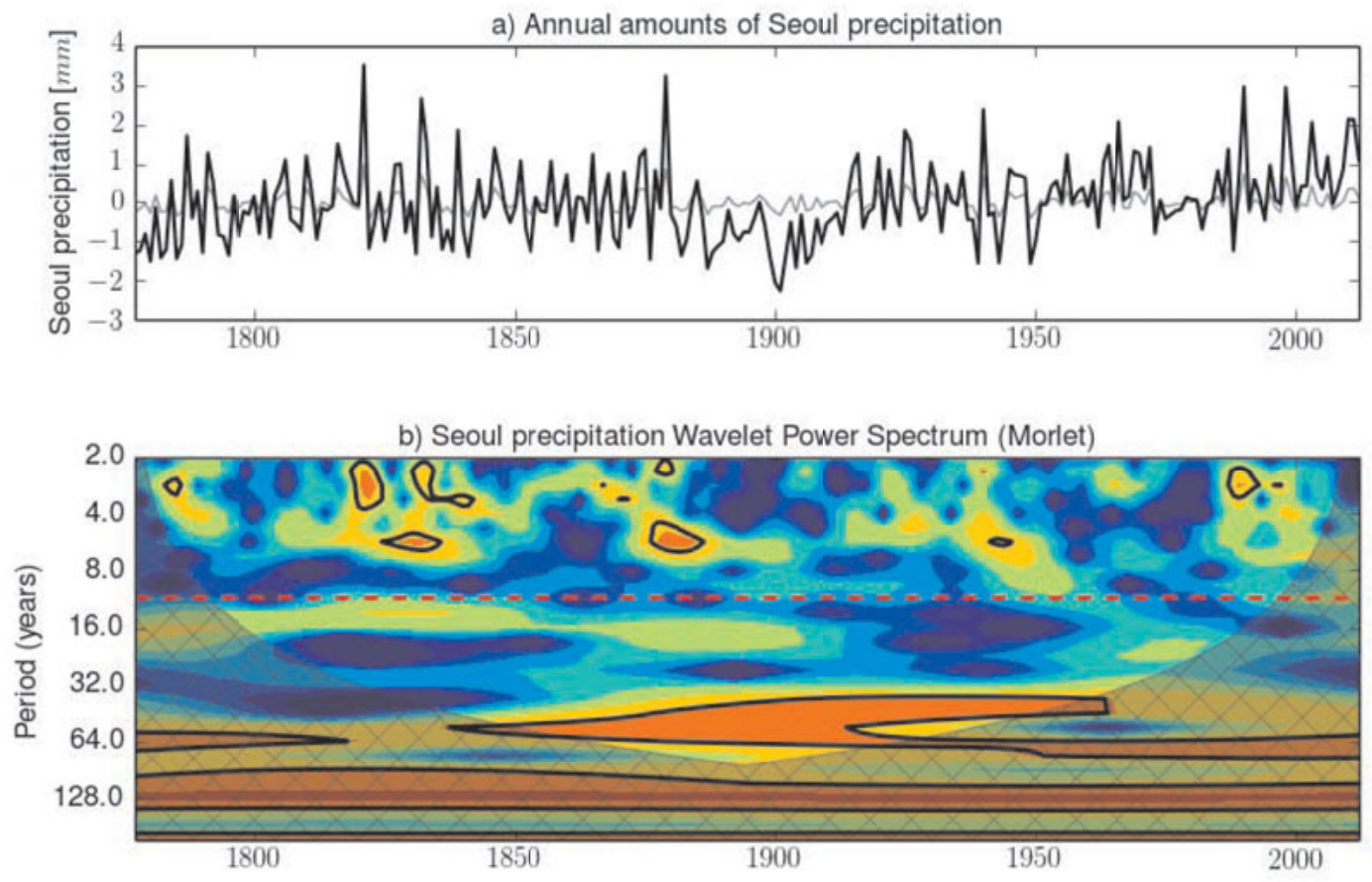

c) Global Wavelet Sp.

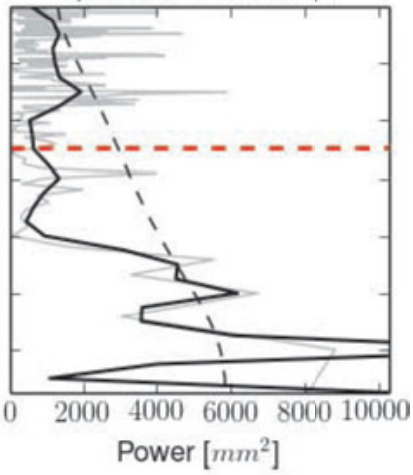

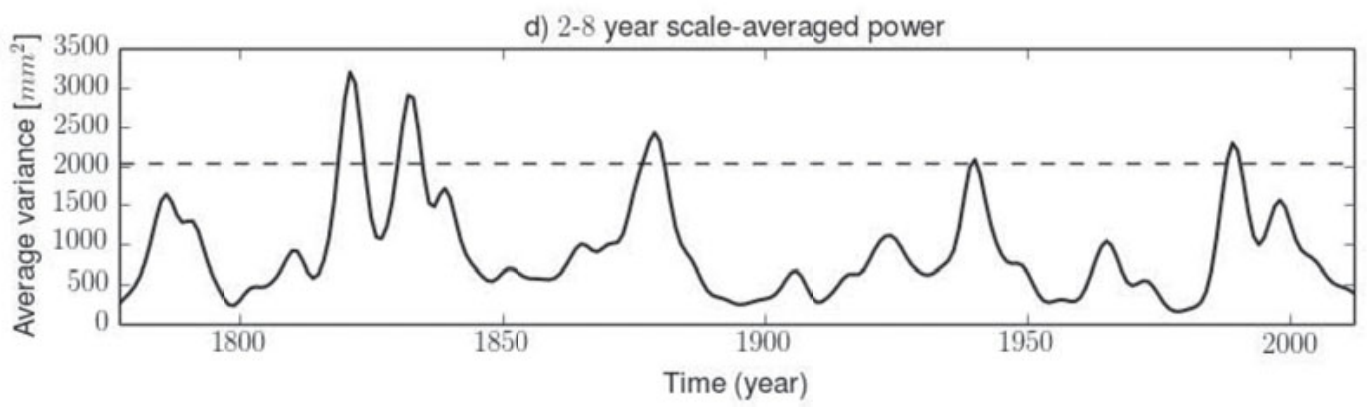

Figure 3. Wavelet analysis of the annual amounts of rainfall in Seoul: (a) the normalized time series of the annual amounts of precipitation in a solid line and residuals from wavelet transform in the grey, (b) wavelet spectra as a function of time and period, and (c) the global wavelet spectra. (d) The temporal change of the power of the 2-8 years period components. The thick contours in (b), the black dashed curve in (c), and horizontal dashed line in (d) denote the significance level of $5 \%$. The dashed red lines in (b, c) denote the position of $11-$ year period.

Figura 3. Análisis wavelet de los totales anuales de lluvia en Seúl: (a) las series temporales normalizadas de los totales anuales de precipitación en línea sólida y los residuos de la transformación wavelet en gris, (b) espectro wavelet como una función del tiempo y período, $y$ (c) el espectro wavelet global. (d) El cambio temporal de potencia de los componentes de períodos entre 2 y 8 años. Los contornos gruesos en (b), la curva negra discontinua en (c) y la línea horizontal discontinua en (d) denotan el nivel de significación del $5 \%$. Las líneas rojas discontínuas en $(b, c)$ denótan la posición del período de 11 años.

suppression behaves in opposite way compared with a shift of the peak in the frequency domain.

\section{Modulation and the frequency change}

\section{Analytic method}

As a conceptual illustration, let us assume a time series of random numbers multiplied by a cosine function of time, which is presumed to represent the real 11-year solar cycle. In a purely mathematical approach, we can express ideal white noise with a power amplitude of one unit as a function of frequency only. Then, we can express a modulated time series as following by considering the Fourier transform of a given random process.

$$
M(t)=A \cos \left(2 \pi f_{0} t\right) \cdot B \sum_{f_{k}=-\infty}^{+\infty}\left[\cos \left(2 \pi f_{k} t\right)+\sin \left(2 \pi f_{k} t\right)\right]
$$

In the above formula, the summation represents a 

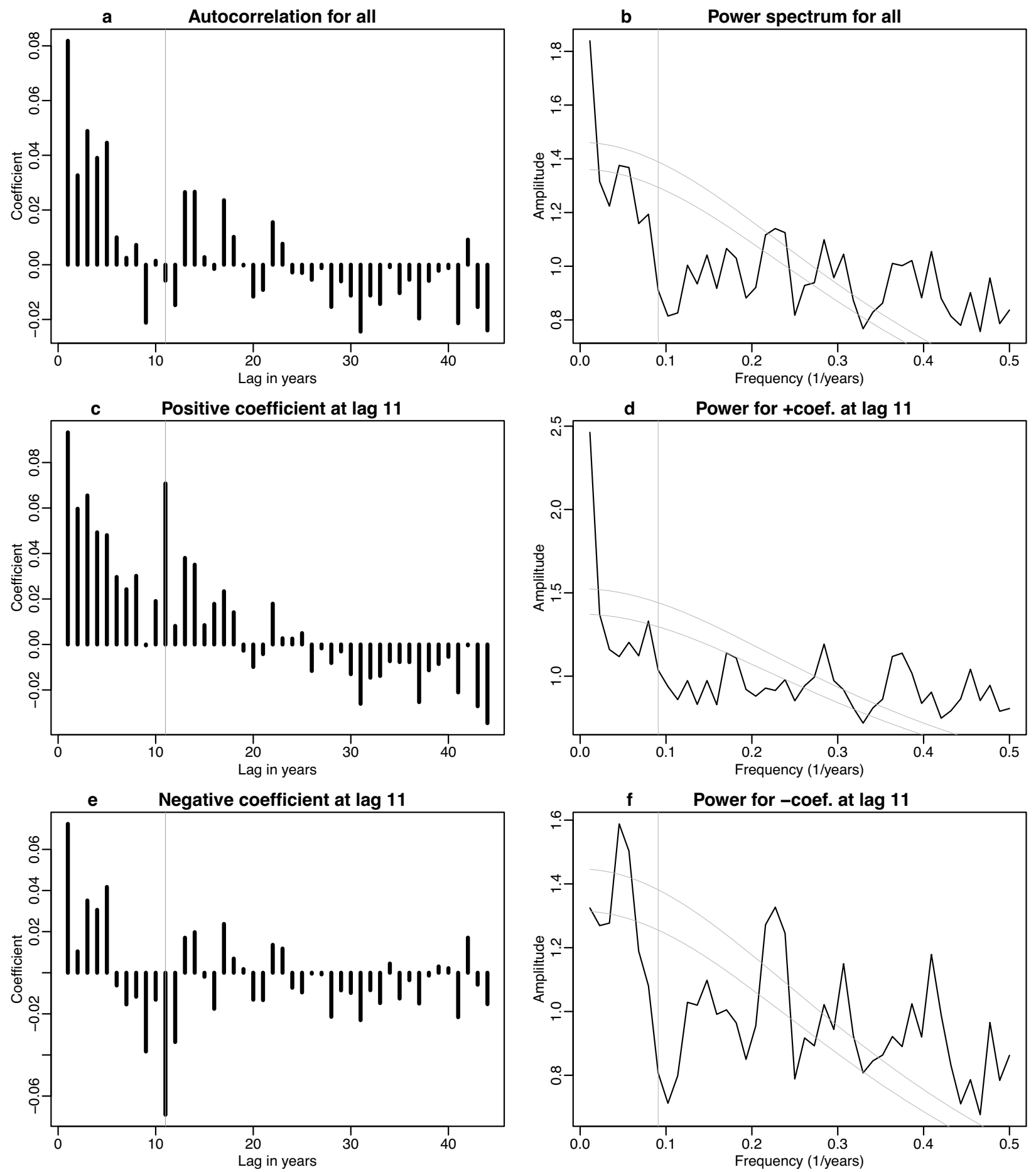

Figure 4. Autocorrelations and power spectrum functions averaged for categorized stations: (a) and (b) for all 3065 stations, (c) and (d) for 1386 stations with positive autocorrelation at lag 11 years, and (e) and (f) for 1679 stations with the negative correlation. The grey vertical bars denote the position of lag 11 years in the left-hand side figures and 1/11 frequency component in the right-hand. The paired grey curves on the right show the range of red-noise spectrum power with a confidence level of $95 \%$ by assuming the normal distribution of the frequency power of all the stations.

Figura 4. Funciones de autocorrelación y espectro de potencia promediadas para las estaciones categorizadas: (a) y (b) para todas las 3065 estaciones, (c) y (d) para las 1386 estaciones con autocorrelación positiva en el paso de los 11 años, y (e) y (f) para 1679 estaciones con la correlación negativa. Las barras verticales grises denotan la posición del paso de 11 años en las figuras de la derecha y el componente correspondiente a la frecuencia 1/11, en las figuras de la izquierda. La pareja de curvas grises en las figuras de la derecha muestran el rango de un espectro de potencia de ruido rojo con un nivel de confianza del 95\% al asumir la distribución normal de las frecuencias de potencia de todas las estaciones. 
white noise time series. For a strictly random process, it is not reasonable to represent the random series with deterministic sinusoidal functions. For us, however, it is useful to track the effects of the forcing frequency component in the modulated time series. The symbols $A$ and $B$ represent the amplitudes of the forcing time series and forced random noise process, respectively. In the above form of modulation, it is clear that the relative amplitudes $A$ and $B$ do not significantly affect the final output. The spectrum width and regularity in time of the forcing is much more important than its amplitude. In the expression, we only consider a forcing time series with a line spectrum, in other terms no half-width. By using the trigonometric relation, we can express the new spectrum components produced by modulation.

$$
M(t)=\frac{A B}{2} \sum_{f_{k}=-\infty}^{+\infty}\left[\cos \left\{2 \pi\left(f_{k} \pm f_{0}\right) t\right\}+\sin \left\{2 \pi\left(f_{k} \pm f_{0}\right) t\right\}\right]
$$

Therefore, we have a new set of frequencies after modulation of the random time series with a sinusoidal one. In the expression, $F \pm G=F+G+F-G$ for arbitrary operands $F$ and $G$. The symbol \pm in the following equation has a conventional meaning.

$$
f_{\text {mod }}=f_{k} \pm f_{0}
$$

The change of power in frequency after modulation can be inferred from the above expression. Each frequency except for $f_{0}$, releases and regains equal amounts of power, so the net change is null after modulation. The absence of power at the frequency zero (0) reduces that of the forcing frequency by half in the modulated time series (Fig. 5).

\section{Numerical experiments}

The ideal random time series has a unit power for each frequency. In a numerical process for a finite length of data, the frequency expands from 0 to the Nyquist frequency 0.5 for the time series with a unit time interval. In the time domain, multiplication between a sinusoidal variable in time and a random time series has a different outcome compared with the addition of the two series. The latter is a linear process and the former tends to represent nonlinear process. The modulation of a pure random time series reduces the power of the sinusoidal forcing frequency by half, as already explained above.

Another suppression, which is notable in Figure $6 a$, near the Nyquist frequency comes from the even number of samples, which are used to produce the random time series. At the Nyquist frequency, its power in the modulated time series is the sum of $\cos (n \pi)$, for $n=0,1, \ldots, N-1$. If $N$ is even, the Nyquist frequency component has zero amplitude. For odd numbered samples, the Nyquist frequency has a unit amplitude for the normalized series.

Addition or multiplication of the forcing and the random time series for modulation shows strikingly different outcomes, as is evident in Figure 6. The peak resulting from addition is stable but multiplication does not produce exactly the same result for each generated data set. However, the suppression always appears.

Variation of precipitation caused by solar variation seems to be affected by changes in the atmospheric stability rather than a direct relationship between the amounts of precipitation and the intensity of solar activity (Gu and Adler, 2011). Their interpretation is consistent with the results from our analysis of obser-

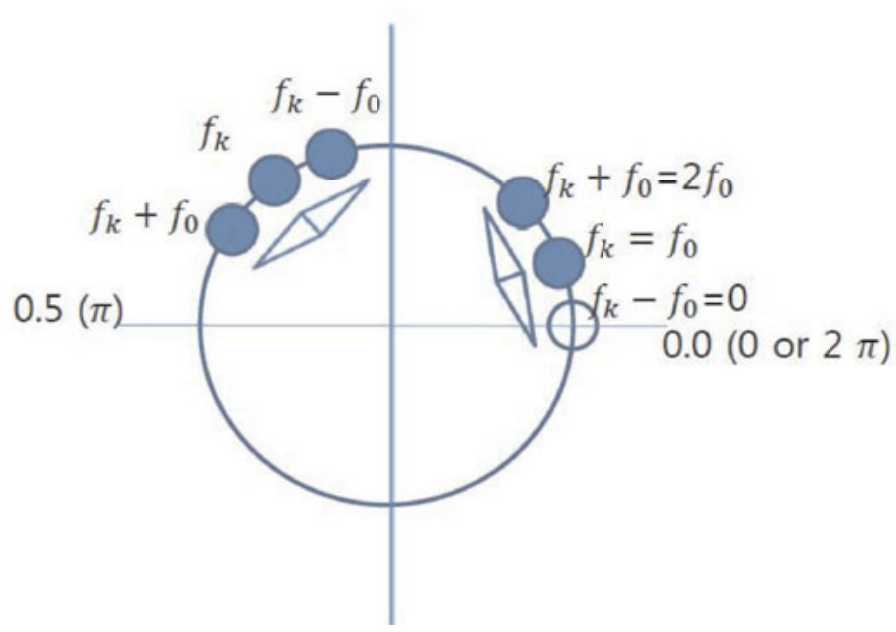

Figure 5. A schematic to illustrate the change of frequency power by modulation. Modulation is done by multiplying a sinusoidal function with frequency $f_{o}$ in time to the random series with all frequency $f_{k}$ and with a constant amplitude. The compass needle shape denotes the direction of power transfer by modulation. The small empty circle denotes no amplitude or power for the zero (0) frequency. Consequently, $f_{0}$ does not get half power from the zero (0) frequency while it gets it from the frequency $2 f_{0}$. The power of $f_{0}$ decreases to the half of the original because it transfers its power to frequencies of zero $(0)$ and $2 f_{0}$.

Figura 5. Un esquema para ilustrar el cambio de las frecuencias de potencia por modulación. La modulación se realiza por la multiplicación de una función sinusoidal con una frecuencia $f_{0}$ en relación a una serie aleatoria con todas las frecuencias $f_{k} y$ con una amplitud constante. La forma de la aguja de brújula denota la dirección de la transferencia de potencia por modulación. El pequeño círculo vacío denota la ausencia de potencia o amplitud para la frecuencia cero (0). Consecuentemente, $f_{0}$ no toma la mitad de la potencia desde la frecuencia cero (0) mientras que si la toma de la frecuencia $2 f_{0}$. La potencia de $f_{0}$ disminuye a la mitad del original porque transfiere su potencia a frecuencias de cero $(0)$ y $2 f_{0}$. 

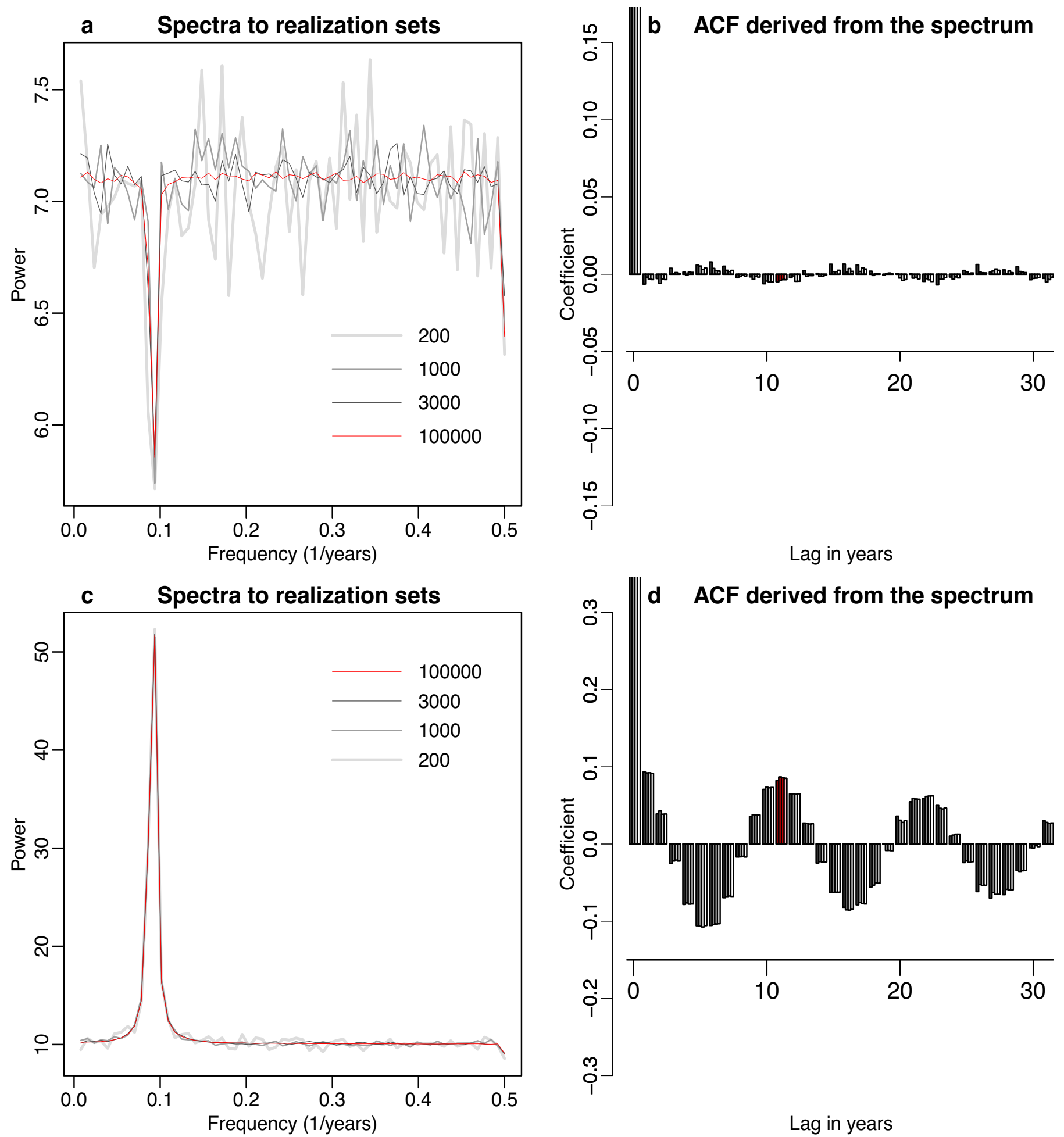

Lag in years

Figure 6. The spectrum functions and autocorrelations of the random time series with 124 samples, modulated by a sinusoidal time series with an 11-year period. ( $a$ and b) Based on multiplication and ( $c$ and d) addition of the two series. The digits of the legends denote the number of modulated time series for the individual curves. The samples are 124 by considering the averaged data period of 120.4 years for the selected GHCN stations.

Figura 6. Las funciones de espectro y autocorrelación de las series temporales con 124 muestras, moduladas por una serie temporal sinusoidal con un período de 11 años. (a y b) Basadas en multiplicación, y ( $c$ y d) suma de las dos series. Los dígitos de las leyendas denotan el número de series temporales moduladas por las curvas individuales. Las muestras son 124, al considerar los datos medios de período de 120.4 años de las estaciones GHCN seleccionadas. 
vations. The 11-year frequency is depressed, virtually contradicting the common sense interpretation that a stronger sun causes more (or less) precipitation amounts. In other words, the amount of precipitation is not directly proportional to the sun's strength. If the previous proportional mechanism were working, we would see a strong and robust 11-year spectrum peak instead of the observed suppression.

The spectrum peak is expected to stem from the amplitude increase of the 11-year solar cycle by the multiplication of the time mean values of precipitation. The mean value or the power of the zero frequency is fundamental in the modulation to produce an enhanced 11-year frequency peak rather than suppression. The inherent tendency of precipitation is a strong randomness and white noise-like change in time, which may result in virtually no interaction between the stationary component of precipitation and the solar signal.

We tested the spectrum broadness of the forcing time series by increasing its band width. The forcings with a broad spectrum produced a weak suppression in general. The results are variable for each calculation set, which suggests an acute sensitivity to the well-defined sinusoidal oscillation rather than to the forcing with a broad spectrum. This allowed us to clearly differentiate our 9-year through 11-year frequency components from those probably originating from the El Nino phenomenon. Such differentiation conforms to a very weak link between the temporal power changes of the Seoul precipitation (Fig. 3d) and the Nino3 sea surface temperature in Figure 8 of (Torrence and Compo, 1998).

The dependence of results on the broadness of the frequency band of the forcing time series is consistent with previous findings (Friis-Christensen and Lassen, 1991). They found that the length of the solar cycle period is proportional to the average temperature of the northern hemisphere. The level of broadness of spectrum distribution reflects the deviation from the strong regular variation in time. This seems to suggest that the time rate of change of the solar cycle is more important than its absolute strength in affecting precipitation amounts.

\section{Conclusions}

For the precipitation in Seoul, autocorrelation values exceeding a noise level for lag 11 years were obvious, and there appeared to be a weak but noticeable suppression in the spectrum function for the 11-year frequency as is discernible in Figures $3 b$ and $3 c$. The feature was global in space and time and was almost time-independent, as shown in Figures 3 and 4. The appearance of the suppression is stable irrespective of the number of samples for greater than roughly 100.

Even the results for each station were variable the suppression was always differentiable by its magnitude from the other frequencies. Therefore, for comprehensive analysis of precipitation, both the autocorrelation and spectrum function were necessary because the Seoul rainfall shows an ambiguous spectrum signature but an unmistakable correlation value. This type of signal is not only confined to Seoul. There are around one thousand five hundred stations revealing such tendencies, which can be inferred from Figure 4b.

Globally the suppression in the spectrum function is more easily discernible than the enhancement of the autocorrelation at lag 11 years. The frequency or period of the suppression is displaced slightly toward the shorter periods. Such a shift of the 11-year signal might be associated with the exact period of the solar signal being shorter than 11 years and the reddening of the time series, which results from the intermittency and regime change of precipitation.

Despite a small mismatch between the 11-year solar signal and our observations, we assumed that the 11-year frequency suppression was due to the 11year periods of sunspot numbers. We checked the possibility of our assumption by applying a sinusoidal forcing to the nearly white noise variation. These kinds of random variation did not have any notable effects on the results. As for the distribution of random time series, we tested normal distribution, gamma distribution, and skewed random variable. The results were almost the same (not shown). The suppression is sensitive to the number of total time series for computation, or in other words the observation sites. It is also affected by the spectrum band width of the forcing.

Mathematically autocorrelation is the same as power distribution in the spectrum through a Fourier transform pair. However, they produced differing levels of impression to signals for the precipitation time series. By taking into account various aspects of the observations, we proposed a model for the forcing of solar signals to precipitation. It is pertinent to consider the relationship between the solar signal and precipitation as multiplicative rather than additive, which is intrinsically nonlinear in their interaction. A simple analytic illustration, as well as numerical experiments, supports our assumption.

Rainfall seems to be modulated nonlinearly by the 11-year cycles. The strength of the modulation may be much stronger than we previously expected. To 
assess the modulation level, we require additional information about the nonlinear interaction system. For numbers larger than about 128 samples and 200 realizations of calculation, the numerical results were stable, which means that they always produce similar shapes and noticeable suppression.

The enhancement or suppression of the 11-year frequency power depends on the power spectra of the original rainfall time series, which reflects the precipitation regimes at a station. When we try to find a signal related to solar effects, it is critical that the precipitation regime must be persistent for a given station. According to the physical mechanisms proposed by (Gu and Adler, 2011), and from the analysis results, solar variation seems to affect precipitation through a phase shift of the precipitation events rather than by controlling the amount of precipitation directly.

The suppression of the power of a certain frequency is possible through the multiplication of a sinusoidal time series with the white noise values in the time domain. Despite the average feature of the power suppression of the forcing frequency, the affection level of the sunspot signals may differ from station to station.

\section{Acknowledgements}

This research was funded by the Korea Meteorological Administration Research and Development Program under Grant Cater 2014-3062 and also by the Brain Korea 21 Plus Project (through the SEES of SNU) in 2014.

\section{References}

Balmforth, N. J., Provenzale, A., Spiegel, E., Martens, A., Tresser, C., and Wu, C. W., 1999. Red spectra from white and blue noise. Proceedings of the Royal B 266, 311-314.

Chun, Y., and Jeon, S.-W., 2005. Chugugi, Supyo, and Punggi: Meteorological instruments of the 15th century in Korea. History of Meteorology 2, 25-36.

Friis-Christensen, E., and Lassen, K., 1991. Length of the solar cycle: An indicator of solar activity closely associated with climate. Science, 254, 698-700.

Gu, G., and Adler, R. F., 2011. Precipitation and Temperature Variations on the Interannual Time Scale: Assessing the
Impact of ENSO and Volcanic Eruptions. Journal of Climate, 24, 2258-2270.

Hartmann, D. L., 1994. Global Physical Climatology. Academic Press, pp. 411.

Jung, H.-S., Lim, G.-H., and Oh, J.-H., 2001. Interpretation of the Transient Variations in the Time Series of Precipitation Amounts in Seoul, Korea. Part I: Diurnal variation. Journal of Climate, 14, 2989-3004.

Jung, H.-S., Park, J.-S., Lim, G.-H., and Oh, J.-H., 2000. Trend analysis and wavelet transform of time series of precipitation including the Chukwookee observation in Seoul. The Korean Journal of Applied Statistics, 13, 525-540.

Kim, S. S., 1988. Comments on the Chinese claim for the invention of Chukwookee. Selected Papers of Kim, S. S., Hakye-Sa, 427-440. (In Korean).

Kim, S. S., 1976. A Study on Summer Precipitation and Winter Temperature at Seoul. Journal Korean Meteorological Society, 12, 1-5 (in Korean).

Kossin, J. P., Camargo, S. J., and Sitkowski, M., 2010. Climate modulation of North Atlantic hurricane tracks. Journal of Climate, 23, 3057-3076.

Labitzke, K., and van Loon, H., 1993. Some recent studies of probable connections between solar and atmospheric variability. Annals of Geophysics, 11, 1084-1094.

Lim, G.-H., Suh, Y.-C., and Kim, B.-M., 2006. On the Origin of the Tropical Atlantic Decadal Oscillation based on the Analysis of the ICOADS. Quarterly Journal of the Royal Meteorological Society, 132, 1139-1152.

Lim, G.-H., and Suh, A.-S., 2000. Diurnal and Semidiurnal Variations in the Time Series of 3-Hourly Assimilated Precipitation by NASA GEOS-1. Journal of Climate, 13, 2923-2940.

Parthasarathy, B., Rupa Kumar, K., and Munot, A. A., 1991. Evidence of secular variations in Indian monsoon rainfallcirculation relationships. Journal of Climate, 4, 927-938.

Torrence, C., and Compo, G. P., 1998. A Practical Guide to Wavelet Analysis. Bulletin of the American Meteorological Society, 79, 61-78.

van Loon, H., and Labitzke, K., 1998. The Global Range of the Stratosphere Decadal Wave. Part I: Its Association with the Sunspot Cycle in summer and in the Annual Mean, and with the Troposphere. Journal of Climate, 11, 15291537.

Wang, B., Jhun, J.-G., and Moon, B.-K., 2007. Variability and Singularity of Seoul, South Korea, Rainy Season (17782004). Journal of Climate, 20, 2572-2580.

Wang, B., Ding, Q., and Jhun, J.-G., 2006. Trends in Seoul (1778-2004) summer precipitation. Geophysics. Res. Lett., 33, L15803, doi:10.1029/2006GL026418.

Zhang, D., 1999. Climate Variation of Wetness in Eastern China over the Past Millennium. Bulletin of the National Museum of Japanese History, 81, 31-39.

Recibido: septiembre 2016

Revisado: diciembre 2016

Aceptado: enero 2017

Publicado: septiembre 2018 